\title{
Knowledge of fruits and vegetables, consumption pattern and associated factors among adults in Lagos State, Nigeria
}

\author{
*Olatona F.A. ${ }^{1}$, Sosanya A. ${ }^{1}$, Sholeye O.O. ${ }^{2,}$ Obrutu O.E. ${ }^{1}$, Nnoaham K.E. ${ }^{3}$
}

\begin{abstract}
Objective: Low fruit and vegetable consumption is a major global risk factor for morbidity (associated with micronutrient deficiencies) and premature mortality; meanwhile, little is known about the adequacy and consumption pattern in Lagos, Nigeria. This study therefore determined knowledge, patterns, adequacy and factors associated with fruits and vegetables consumption among adults in Lagos, Nigeria.
\end{abstract}

Methods: This was a cross-sectional descriptive study that employed a multistage sampling method to select 330 adults from one local government area in Lagos State. Data was collected using structured interviewer-administered questionnaires. Questions on knowledge were scored and the total obtainable score was 13. The percentage of the score obtained out of the total obtainable score (13) was used in grading the level of knowledge. Adequacy of fruit and vegetable intake was regarded as consuming an average of at least five (5) servings of fruits and vegetables per day within the previous one week before the study. Data was analyzed using Epi info version 7 and Chi-square was used to determine associations between categorical variables.

Results: Majority of the respondents were males (60.6\%), between age 19 to 38 years $(69.4 \%)$ and had at least secondary school education (93\%). Only $24.9 \%$ of respondents had a 'good' level of knowledge while $27.0 \%$ consumed 'adequate' amount of fruits and vegetables. Orange and pumpkin were the most frequently consumed fruit and vegetable respectively. Educational status, income, female gender and marriage were associated with adequate intake of fruits and vegetables $(p<0.05)$.

Conclusion: Knowledge and prevalence of adequate intake of fruits and vegetables were low especially among young unmarried men who are of low socio-economic status in Lagos. Orange and pumpkin were the most frequently consumed fruit and vegetable. Efforts to increase public awareness about fruits and vegetables should be targeted towards younger unmarried males of low socioeconomic status.

Keywords: Fruit, vegetables, knowledge, consumption pattern, adequacy

\author{
*Correspondence author \\ Olatona F.A.,Email: folaton@gmail.com \\ http://orcid.org/0000-0002-7766-0117 \\ Email: toyeolajide@yahoo.co.uk
}

'Department of Community Health \& Primary Care, College of Medicine, University of Lagos, Nigeria.

Email: folaton@gmail.com

${ }^{2}$ Department of Community Medicine, Olabisi Onabanjo University, Ogun State, Nigeria.

${ }^{3}$ Faculty of Health \& Human Sciences, Plymouth University, England.

Research Journal of Health Sciences subscribed to terms and conditions of Open Access publication. Articles are distributed under the terms of Creative Commons Licence (CC BY-NC-ND 4.0). (http://creativecommons.org/licences/by-nc-nd/4.0).

http://dx.doi.org/10.4314/rejhs.v6i2.2 


\title{
Connaissance en matière de fruits et légumes, habitude de consommation et facteurs afférents chez les adultes dans l'état de Lagos au Nigéria.
}

\author{
*Olatona F.A. ${ }^{1}$, Sosanya A. ${ }^{1}$, Sholeye O.O. ${ }^{2,}$ Obrutu O.E. ${ }^{1}$, Nnoaham K.E. ${ }^{3}$
}

\section{Résumé}

Objectif: La faible consommation de fruits et légumes est un risque majeur mondial de morbidité (associée à la carence en micronutriments) et de mortalité prématurée. Entre-temps, le niveau de suffisance et l'habitude de consommation dans la ville de Lagos au Nigeria sont méconnus. Cette étude visera donc à déterminer le niveau de connaissance, les habitudes, le niveau de suffisance et les facteurs associés à la consommation des fruits et légumes chez les adultes dans la ville de Lagos au Nigeria.

Méthodes: Il s'agissait d'une étude descriptive transversale qui s'appuie sur une méthode d'échantillonnage à plusieurs degrés pour sélectionner 330 adultes d'une commune de l'état de Lagos. La collecte de données s'est faite par des questionnaires structurés administrés par l'intervieweur. Les questions portant sur la connaissance ont été évaluées sur une note totale de 13. Le pourcentage de notes obtenues sur le total de notes pouvant être obtenues (13) a servi à évaluer le niveau de connaissance. La consommation de 5 fruits et légumes par jour pendant la semaine qui a précédé l'enquête était considérée comme la norme de mesure du niveau de suffisance de consommation de fruits et légumes.

L'analyse des données s'est faite à l'aide de l'Epi Info version 7 et Chi Square afin de déterminer la relation entre les différentes variables.

Résultats: La majorité des personnes interrogées était des hommes (60,6\%), âgés de 19 à 38 ans $(69,4 \%)$ ayant un niveau de scolarisation d'au moins l'école secondaire (93\%), seuls $24,9 \%$ des personnes interrogées avaient un «bon » niveau de connaissance, tandis que $27,0 \%$ consomment une quantité suffisante de fruits et légumes. Les fruits et légumes les plus consommés étaient les oranges et les citrouilles respectivement. L'éducation, le niveau des revenus, le genre féminin et le mariage étaient liés à la consommation en quantité suffisante de fruits et de légumes $(\mathrm{p}<0,05)$.

Conclusion: La connaissance et la prévalence en matière de consommation de fruits et de légumes sont particulièrement faibles chez les jeunes hommes célibataires de niveau socio-économique bas dans l'état de Lagos. Les fruits et légumes les plus consommés sont les oranges et les citrouilles. Des efforts doivent être déployés pour sensibiliser à la consommation des fruits et légumes avec pour cible les jeunes hommes célibataires de classe socio-économique faible.

Mots Clés: Fruits, légumes, connaissance, habitude de consommation, niveau de suffisance.

\author{
*Correspondence author \\ Olatona F.A., Email: folaton@gmail.com \\ http://orcid.org/0000-0002-7766-0117 \\ Email: toyeolajide@yahoo.co.uk
}

\footnotetext{
${ }^{1}$ Department of Community Health \& Primary Care, College of Medicine, University of Lagos, Nigeria.

Email: folaton@gmail.com

${ }^{2}$ Department of Community Medicine, Olabisi Onabanjo University, Ogun State, Nigeria.

${ }^{3}$ Faculty of Health \& Human Sciences, Plymouth University, England.
} 


\section{INTRODUCTION}

Fruit and vegetable intake is an indicator of a healthy overall diet. "Specifically, total fruit (whole fruit and $100 \%$ fruit juice) and whole fruit intake are the second and third most correlated factors with an overall healthy eating pattern, respectively, after amount of empty calories consumed" (1). It has also been described as an appropriate diet for weight management and protection against overweight and obesity (2). They also play a role in reducing or even reversing the usual degenerative changes that occur with increasing age such as gradual reduction in cell numbers, graying of the hair and reduced respiratory capacity (3).

The WHO estimates that 1.7 million $(2.8 \%)$ deaths yearly around the world is accounted for due to inadequate intake of fruits and vegetables. Globally, low fruits and vegetables consumption accounts for $14 \%$ of gastrointestinal cancer deaths, $11 \%$ of ischemic heart disease deaths and about $9 \%$ of stroke deaths (4). Low fruit and vegetable consumption is responsible for $1.8 \%$ of the total global disease burden.

The World Health Organization (WHO) estimates that in $2020,75 \%$ of deaths in the developing nations will be caused by NCDs which constitute a major public health challenge (3). These diseases (including heart diseases, diabetes mellitus, stroke, cancer and chronic respiratory diseases) now outstrip communicable diseases in reasons for medical hospitalizations in Nigeria, keeping in line with global trends (5). Studies reveal that a "Mediterranean diet"- which is high in fruit and vegetables substantially lowered the risk of incidence and mortality from myocardial infarction compared to a low fat diet; while results from another study showed that a low fat diet enriched with fruits and vegetables, compared with a standard low fat diet, was associated with a reduction in cardiac events and mortality of 40 percent and 45 percent respectively (4).

Fruits and vegetables provide a diversified, flavored, colorful, tasty, low caloric, and protective, micronutrient rich diet (6). They also contain dietary fibres (7). and prolong satiety (8). Consumption of fruits and vegetables, an important element of a healthy diet has been honed as a vital component of a healthy lifestyle which is important in the prevention of many non-communicable diseases (NCDs) such as cardiovascular diseases (CVD) and cancers, if consumed daily and in sufficient amount (9).
Increasing the consumption of fruits and vegetables has been shown to lower the rates of oesophageal, gastric, colorectal and lung cancers with these outcome reducing the global disease burden of each by $20 \%, 19 \%, 2 \%$ and $12 \%$. It also plays a role in the prevention of laryngeal and pharyngeal cancers (10). There is a high prevalence of micronutrient deficiencies in developing countries and it has been attributed to the low knowledge of the nutritional value of fruits and vegetables as well as their low consumption, despite their relative availability and cultural acceptance (8) as well as a predisposition towards energy-dense, sugarsweetened foods.

Many developing nations, including Nigeria however lack sufficient and reliable data on fruit and vegetable consumption in their populations (11). Meanwhile, the data retrieved from a global survey revealed that countries from the African region such as Congo, Cote d'Ivoire and Ghana among other countries showed the greatest heterogeneity in fruit and vegetable consumption (6) thus making it impossible to adopt their data for use. In Nigeria, traditional diets rich in vegetables and micronutrients are being substituted with fast foods and pastries. With an increased westernization of lifestyles, several working-class adults may continually feel the urge for consumption of convenience foods often devoid of fruits and vegetables. Lagos, being a commercial and cosmopolitan city, offers a wide variety of food choices, with several fast food and pastry outlets. The adult population, with the economic and social freedom to decide whatever they want to eat, suffer the effect of low consumption of fruits and vegetable more in terms of non-communicable diseases. Meanwhile the few existing studies have focused more on knowledge and consumption of fruits and vegetables among secondary school students $(2,12,13)$. Little is known about the knowledge, adequacy and consumption pattern among adults in Lagos. This study therefore determined the knowledge, adequacy, pattern and factors associated with fruits and vegetable consumption among adults in Lagos, Nigeria.

\section{MATERIALS AND METHODS}

A descriptive cross-sectional study was conducted among adults (eighteen years and above) residing in two urban communities in Lagos, between February and August 2017. The minimum sample size was calculated using Cochran's formula $\left(\mathrm{N}=\mathrm{Z}^{2} \mathrm{pq} / \mathrm{d}^{2}\right)$ and ' $\mathrm{p}$ ' as 
prevalence of adults who had adequate intake of fruits and vegetables in a previous Nigerian study (69\%) (14). The calculated minimum sample size was 329 but it was increased by $10 \%$ to obtain 361 in order to make allowance for non-response.

Sampling technique: Multistage random sampling technique was used to select the respondents. One local government area (LGA) was selected using simple random sampling technique (ballot method) and its name is Surulere LGA. Two (2) wards were selected from the local government area while ten (10) streets were selected from each ward using simple random sampling technique (ballot method) to obtain 20 streets. On each street, the starting point for administration of the questionnaire was determined by balloting between numbers 1-10. Thereafter, systematic random sampling was employed to select houses with a sampling interval of two (2). One household was selected from each house while one adult was selected from each household using simple random sampling technique (balloting).

Variables: The independent variables in this study include socio-demographic and economic characteristics of the respondents such as age as last birthday, sex, marital status, level of education and income while the dependent variables include knowledge of fruits and vegetables, adequacy of intake and consumption pattern. Definition of adequacy of intake was based on $400 \mathrm{~g}$ or 5 servings of fruits and vegetables per day recommended by the World Health Organization (WHO).

Data collection: Data was collected from respondents using interviewer-administered questionnaire. The questionnaire was categorized into three sections; Section A elicited sociodemographic characteristics of the respondents; Section B determined knowledge about fruits and vegetables and its role in human health; Section C identified the pattern of consumption of fruits and vegetables including the number of servings of all fruits and vegetables consumed within the previous one week (15).

Pretesting of questionnaire was done in Ikeja Local government area (which is similar but far from the study site) with a view to testing the reliability of the instrument (detecting deficiencies or ambiguities in the questionnaires and making appropriate corrections). Necessary adjustments were made on the questionnaires especially addition of other fruits and vegetables consumed in Lagos.

Three research assistants (undergraduate medical students) were trained to obtain informed consent and administer the questionnaire. Serving size for fruit and vegetables was explained thoroughly to the interviewers (A standard serving size is $80 \mathrm{~g}$ which is equals to approximately one small banana or apple or orange or three heaped tablespoons of cooked vegetables). Change in habits as a result of being assessed which can introduce a bias to the study was avoided by completing data collection on the same day for each participant.

Ethical considerations: The study was conducted according to the guidelines laid down in the Declaration of Helsinki. Ethical approval was obtained from the Health Research and Ethics Committee of the Lagos University Teaching Hospital (The approval number is ADM/DCST/HREC/APP/1316). Permission was obtained from the authority of the local government area. Written informed consent was obtained from each respondent before the questionnaires were administered. Confidentiality was assured and maintained throughout the period of the study.

Data analysis: The data obtained were analyzed electronically using epi-info 7 statistical software (version 1.1.6). The total score obtainable for knowledge was 13 . The level of knowledge was graded into 'good', 'fair' and 'poor'. The level of knowledge was rated to be 'good' if the respondent scored $\geq 60 \%$ of total obtainable score (8-13). Those who scored $40-59 \%$ (5-7) were rated to have 'fair' knowledge while those who scored less than $40 \%(<5)$ were rated to have 'poor' knowledge.

Adequacy of consumption was assessed by asking for the number of portions of all fruits and vegetables consumed during the previous week before the study and dividing the total number of portions consumed per week by seven to obtain average number of portions consumed per day (15). The amount consumed was regarded as 'adequate' if the average portions of fruits and vegetables consumed were five (5) or more per day. Consumption was 'inadequate' if the average portions of fruits and vegetables consumed were less than five (5) per day. A Chisquare test was used to test for significant associations between categorical variables. A $p$ - 
value of $<0.05$ was considered statistically significant.

\section{RESULTS}

A total of 360 questionnaires were administered but 330 questionnaires were retrieved and analyzed. The response rate was $91.67 \%$. Most of the respondents were males (60.61\%), Christians (64.85\%.) and had at least secondary school education (89.70\%). More than half were single $(51.82 \%), 43.33 \%$ were manually skilled while only $12.43 \%$ were professionals. Almost half $(42.73 \%)$ of the respondents earned between $20,000-50,000$ naira permonth.

\section{Knowledge about fruits and vegetables among adults in Lagos, Nigeria}

Only one quarter $(24.9 \%)$ of the respondents had good knowledge about fruits and vegetables. Knowledge of their preventive properties against diabetes (36.36\%), hypertension $(29.70 \%)$ and obesity was low $(24.55 \%)$ and only a few $(3.33 \%)$ knew that five (5) servings of fruits and vegetables are required daily. (Table 1).

\section{Fruit consumption pattern among adults in Lagos, Nigeria}

Majority $(89.09 \%)$ of the respondents took 1-2 servings of fruit daily. The most preferred fruits were apples $(18.8 \%)$ and oranges $(18.8 \%)$ but the most consumed fruits were oranges $(24.5 \%)$ and watermelon $(24.2 \%)$. The commonest reason for the choice of fruits were taste (27.4\%) and availability (13.7\%). (Table 2 ).

\section{Vegetable consumption pattern among adults in Lagos, Nigeria}

Majority $(96.4 \%)$ of the respondents took 1-2 servings of vegetables daily. The most frequently consumed vegetables were pumpkin (ugu) $(33.6 \%)$ and Celosia (soko) $(8.8 \%)$. The commonest reasons for the choice of vegetables were taste (30.6) and availability (21.2\%). (Table 3 and Figure 1)

\section{Adequacy of daily intake of fruits and vegetables among adults in Lagos, Nigeria}

More than one third of the respondents took only 1 or 2 servings of both fruits and vegetables daily while only $27.0 \%$ of the respondents consumed an adequate amount ( $400 \mathrm{~g}$ or 5 servings) of fruits and vegetables daily. (Table 4, Figure 2).

\section{Factors associated with adequate intake of fruits and vegetables}

There was a statistically significant association between daily intake of fruits and vegetables and sex, marital status, educational status and income of respondents $(\mathrm{p}<0.05)$. (Table 5)

\section{DISCUSSION}

This study shows that adults in Lagos have less knowledge but consumed more fruits and vegetables compared to secondary school students in Lagos and adults in other cities. Unlike previous studies the study revealed the pattern of consumption of fruits and vegetables, and factors associated with knowledge and adequate intake.

Only $24.9 \%$ had 'good' knowledge while $49.4 \%$ had 'fair' knowledge whereas a study among secondary school students in Lagos, Nigeria found $84.9 \%$ to have good knowledge and another study in Plateau, Nigeria revealed that $92.4 \%$ of respondents had fair knowledge $(12,14)$. This finding is consistent with that of a New Orleans study where $39 \%$ of respondents had correct knowledge of fruits and vegetables. (16). Only $3.3 \%$ of the total respondents knew the adequate amount of fruits and vegetables required daily to be $\geq 400 \mathrm{~g}$ or 5 servings. Higher levels of education, professional occupations and higher levels of income were significantly associated with good knowledge $(\mathrm{p}<0.05)$.

Only $27 \%$ of the respondents reported adequate daily intake of fruits and vegetables as recommended by WHO. Other studies reported much lower percentages such as 5.48\% among Junior Secondary School students in Surulere, Lagos, $12 \%$ among adolescents in Ibadan, Nigeria and 12\% (fruits) and 9\% (vegetables) among Americans. $(13,16,17)$. This current study is in consonance with reports from tertiary students in Oyo State, South-Western Nigeria with adequate intake among $29 \%$ and a study of global variability in fruits and vegetable consumption which revealed that $77.6 \%$ of men and $78.4 \%$ of women from 52 mainly low- and middle-income countries consumed less than the minimum recommended five daily servings of fruits and vegetables indicating that only $21.6 \%$ consumed adequate amount. $(18,19)$.

Almost all the respondents consumed their fruits in the fresh whole form, only $0.61 \%$ preferred consuming it as juice/smoothie. A Ghanaian study also reported that $93 \%$ of 
respondents consumed fruits in their raw state. (20). Whole fruit is more beneficial to the body because of the fiber content which enhances weight control and prevention of NCDs. Choice of fruits was influenced by taste $(27.4 \%)$, availability (13.7\%) and health reasons (6.9\%). Few respondents identified cost as a factor affecting their choice of fruits in this study. This is in congruence with another study in Oyo State which identified the above factors as variables that influenced the choice of fruits. Moreover, reports from Ghana included price of the fruits in addition to availability, convenience, and attractiveness as determining factors for choice of fruits $(21,22)$. The most preferred fruits were apples, oranges and pineapples but the stated preference for apple did not reflect in its consumption. Oranges and watermelon were the most consumed fruits. This is consistent with other reports from tertiary institutions in Oyo state and Ghana where banana, watermelon and orange were the most preferred fruits. In this study, the notion that "apples are fruits for the rich" may have informed the decision to choose it as the most preferred fruit whereas the relatively higher cost of purchasing them might have deterred its purchase.

The most frequently consumed vegetables were pumpkin (ugu), celosia (efo soko), and okro while the least consumed was cucumber. This is comparable to the Ghanaian homemakers' study where dark green leafy vegetables, garden eggs and okra were the most frequently consumed vegetables asides tomatoes, onions and pepper. Tomatoes, onions and pepper were excluded from this study because of their ubiquitous use in the preparation of most of the soups in Nigerian culture. They were also excluded from the research among students of tertiary institutions in Oyo state. Pumpkin leaves were also the most preferred vegetable by Oyo State students (32\%). Most respondents in this study ate their vegetables in the cooked form, either with or without soup similarly to the Ghanaian homemakers and polytechnic students. Few respondents consumed vegetables as salad like the counterparts in Ghana. This is due to the culture in most part of sub-Saharan Africa wherein vegetables are routinely used in cooking recipes.

Gender was identified as a significant factor influencing fruits and vegetables consumption $(p<0.05)$. As with reports from other studies in South Africa, Ghana, and Sweden, the females in this study were more likely to consume adequate quantity of fruits and vegetables compared to the males $(23,24)$. A comparative study of fruit and vegetable consumption and physical activity among adolescents in Low-and-Middle-Income Countries showed varied differences in the gender predilection for fruits and vegetable consumption (25). Girls in Algeria and Morocco were found to be more likely to consume adequate amounts of fruits and vegetables, while in four other countries they were less likely to consume the daily recommended servings compared to boys. The study in Oyo State also found that males consumed more fruits than females.

The role of level of education in the knowledge of fruits and vegetables was significant in this study $(\mathrm{p}<0.05)$, as in other studies in Ghana and Nigeria where knowledge of the benefits of fruits and vegetables also increased as level of education increased, ( $p<$ $0.05)$ (14). This probably means that those who have higher level of education understand the benefits of consuming fruits and vegetables more than others. Level of education and income were also statistically significantly associated with frequency of consumption ( $p<0.05)$. There was however a notable exception among those who had not completed any form of formal education where all of them reported adequate consumption of fruits and vegetables despite having poor knowledge about their benefits. This may be because they possibly grew up on farms and had thus, imbibed a culture of consuming fruits and vegetables. The positive relationship between level of income and consumption of fruits and vegetables was also reported in the studies in Ghana and Oyo State.

Limitation: The response obtained on frequency and servings of different fruits and vegetables consumed could have been affected by recall bias since it involved a recall of fruits and vegetables taken over the previous one week before the study.

\section{CONCLUSION}

Knowledge and prevalence of adequate intake of fruits and vegetables were low among adults in Lagos, Nigeria. Oranges and watermelon were the most consumed fruits while pumpkin and celosia (efo soko) were the most consumed vegetables. Educational status, income, female gender and marriage were associated with adequate intake. Increased efforts are needed to increase public awareness of importance of fruits and vegetables and this 
should be targeted towards younger people especially males who are of low-socioeconomic status.

Acknowledgements: The authors wish to acknowledge the Chairman of Surulere Local Government Area in Lagos, for granting the permission to collect data.

Conflict of interest: The authors declare that there is no conflict of interest.

\section{REFERENCES}

1. Guenther P M, Reedy J, Krebs-Smith SM, Reeve B, Basiotis, PP. Development and Evaluation of the Healthy Eating Index-2005 Technical Report $\mathrm{W}$ e $\mathrm{b}$ $\mathrm{s}$ i t e. http://www.cnpp.usda.gov/Publications/HEI/HE I-2005/HEI-2005TechnicalReport.pdf.

2. Tavassoli E, Ramezankhani A, Mirmiran P, Mehrabi $Y$ and Hafez A.A. Knowledge and Perceptions of Obesity Prevention and Consumption of Fruits and Vegetables among High School Girl Students in Shahrekord. British Journal of Medicine and Medical Research. 2015; 6(2); 200-211.

3. Nwaramah JU, Otitoju GTO. Fruit and Vegetable Consumption Pattern and Health Challenges of Elderly ( $\geqq 60$ years) Staff in the University of Nigeria, Nsukka and Enugu Campuses: A Case Study. Pakistan Journal of Nutrition 2014; 13(11): 626-630.

4. WHO. Global Strategy on Diet, Physical Activity and Health. Promoting fruit and vegetable consumption around the world. Information $\mathrm{s} \mathrm{h}$ e e t. A c c e s s i b l e a t. http://www.who.int/dietphysicalactivity/fruit/en (Accessed on April 7, /2016)

5. Ogah OS, Madukwe OO, Onyeonoro UU, Chukwuonye II, Ukegbu AU, Akhimien MO, et al. Cardiovascular risk factors and noncommunicable diseases in Abia state, Nigeria: report of a community-based survey. Int J Med Biomed Res 2013;2(1):57-68.

6. Sachdeva S, Sachdev T.R, and Sachdeva R. Increasing Fruit and Vegetable Consumption: Challenges and Opportunities. Indian J Community Med. 2013; 38(4): 192 -197. doi: 10.4103/0970-0218.120146

7. WHO (2003). Diet, nutrition and the prevention of chronic diseases. Report of a Joint FAO/WHO Workshop on fruits and vegetables for health, 1-3 September, 2004, Kobe,Japan.

8. Bjelland M., Brantsaeter A.L, Haugen M., Meltzer H.M, Nystad W., Anderson L.F. Changes and tracking of fruit, vegetables and sugarsweetened beverages intake from 18 months to 7 years in the Nowergian mother and child cohort study. BMC Public Health. 2013; 13:793. Published online 2013 Aug 30. doi:
10.1186/1471-2458-13-793.

9. Volken T, Ruesch P and Guggisberg J. Fruit and vegetable consumption among migrants in Switzerland. Public Health Nutrition 2012; 16(1), 156-163.

10. Pomerleau J, Lock K, Knai C, McKee M. Effectiveness of interventions and programmes promoting fruit and vegetable intake. Background paper for the Joint FAO/WHO Workshop on Fruit and Vegetables for Health, Kobe, Japan. WHO.

11. WHO Global Infobase. NCD Indicators. Fruit and $\mathrm{V}$ e g e t a ble. A c c e s s i b l e a t https://apps.who.int/infobase/Indicators.aspx on 08/04/2016.

12. Silva OO, Ayankogbe OO, Odugbemi TO. Knowledge and consumption of fruits and vegetables among secondary school students of Obele Community Junior High School, Surulere, Lagos State, Nigeria. J Clin Sci 2017; 14:68-73. A v a i 1 a b 1 e f r o m http://www.jcsjournal.org/text.asp?2017/14/2/68 1204704.

13. Ilesanmi O.S, Ilesanmi F.F and Ijarotimi I.T. Determinants of Fruit Consumption among Inschool Adolescents in Ibadan, South West Nigeria. European Journal of Nutrition \& Food Safety 4(2): 100-109, 2014 Available from: https://www.researchgate.net/publication/27131 5722_Determinants_of_Fruit_Consumption_am

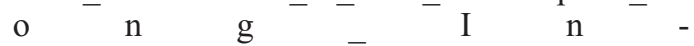
school_Adolescents_in_Ibadan_South_West_Ni geria [accessed Feb 262018 ].

14. Banwat ME, Lar LA, Daboer J, Audu S, Lassa S. Knowledge and intake of fruit and vegetables consumption among adults in an urban community in North Central Nigeria. The Nigerian Health Journal, 2012. (12)1: 12-15.

15. Sauvageot N, Alkerwi A, Albert A, Guillaume M. Use of Food frequency questionnaire to assess relationships between dietary habits and Cardiovascular risk factors in NESCAV study: validation with biomarkers. Nutr J. 2013; 12(1):143. doi: 10.1186/1475-2891-12-143

16. Beech B.M, Rice R, Myers L, Johnson C.C, Nicklas T.A. Knowledge, attitudes, and practices related to fruit and vegetable consumption of high school students. Journal of Adolescent Health, 1999. 24(4):244-50

17. US news. Only one in 10 Americans eat enough fruits and vegetables, CDC study finds. Available from: https://www.theguardian.com/usnews/2017/nov/17/just-12-of-americans-eatenough-fruit-and-vegetables-cdc-study-finds

18. Layade A.A., Adeoye I.B. Fruit and vegetable consumption among students of tertiary institutions in Oyo State. Russian Journal of Agricultural and Socio-Economic Sciences. 2014; $30(6): 3-8$.

19. Hall JN, Moore S, Harper SB, Lynch JW. Global variability in fruit and vegetable consumption. Am J Prev Med. 2009;36(5):402-409. doi: 
10.1016/j.amepre.2009.01.029.

20. Nti C.A, Hagan J, Bagina F, and Seglah M. Knowledge of nutrition and health benefits and frequency of consumption of fruits and vegetables among Ghanaian homemakers. African Journal of Food Science. 2011; 5(6), 333 339.

21. Kpodo F. M., Mensah C., Dzah C.S. Fruit and vegetable consumption patterns and preferences of students in a Ghanaian Polytechnic. World Journal of Nutrition and Health. 2015; 3 (3): 5359. http://pubs.sciepub.com/jnh/3/3/2.

22. Mintah BK, Eliason. Consumption of fruits among students: A case of a public university in Ghana. AJFAND, 2012:12(2). 5978-5993.

23. Peltzer $\mathrm{K}$ and Phaswana-Mafuya N. Fruit and vegetable intake and associated factors in older adults in South Africa. Glob Health Action. 2012; 5: $10.3402 / \mathrm{gha} . \mathrm{v} 5 \mathrm{i} 0.18668$. doi : 10.3402/gha.v5i0.18668 PMCID: PMC3511777.

24. Simunaniemi A, Andersson A, and Nydahl M. Fruit and vegetable consumption close to recommendations. A partly web-based nationwide dietary survey in Swedish adults. F o o d N u t r R e s . 2009 ; 53 : 10.3402 /fnr.v53i 0.2023 . do i : 10.3402/fnr.v53i0.2023 PMCID: PMC2801502.

25. Darfour-Oduro SA, Buchner DM, Andrade JE, and Grigsby-Toussaint DS. A comparative study of fruit and vegetable consumption and physical activity among adolescents in 49 Low-andMiddle-Income Countries. Sci Rep. 2018; 8: 1623. doi: 10.1038/s41598-018-19956-0. PMCID: PMC5785955. 
Table 1: Knowledge about fruits and vegetables among adults in Lagos, Nigeria

\begin{tabular}{lcc}
\hline Knowledge about fruits and vegetables & Freq $(\mathbf{n = 3 3 0})$ & Percent (\%) \\
\hline Characteristics of fruits and vegetables & & \\
Protective foods & 123 & 37.3 \\
Abundant in vitamins & 299 & 71.5 \\
Abundant in minerals & 36 & 10.9 \\
Abundant in fibers & 56 & 17.0 \\
Abundant in antioxidants & 46 & 13.9 \\
Essential part of balanced diet & 306 & 92.7 \\
Useful in weight loss/control & 232 & 70.3 \\
& & \\
Diseases protected by fruits and vegetables & & \\
Hypertension & 98 & 29.7 \\
Diabetes & 120 & 36.4 \\
Obesity & 81 & 24.6 \\
Stroke & 30 & 9.1 \\
Heart diseases & 47 & 14.2 \\
Cancer & 42 & 12.7 \\
Servings required daily & & \\
= 5 servings ( 400g) & & \\
Effect of cooking for long & 11 & 3.3 \\
Destroy and reduce vitamins and minerals & 283 & 85.8 \\
Level of knowledge & & \\
Good & & \\
Fair & & \\
Poor & 82 & 25.9 \\
\hline
\end{tabular}


Table 2. Fruit consumption pattern among adults in Lagos Nigeria

\begin{tabular}{|c|c|c|}
\hline Fruits consumption & Frequency $(n=330)$ & Percentage $(\%)$ \\
\hline \multicolumn{3}{|c|}{ Pattern of consumption } \\
\hline As part of main meal & 8 & 2.1 \\
\hline As snacks alone & 94 & 28.6 \\
\hline Main meal alone & 7 & 2.1 \\
\hline Not planned & 121 & 36.8 \\
\hline \multicolumn{3}{|c|}{ Form of fruits usually consumed } \\
\hline Fresh whole fruits & 317 & 96.1 \\
\hline Frozen fruits & 11 & 3.3 \\
\hline Juice & 2 & 0.6 \\
\hline \multicolumn{3}{|l|}{ Most preferred fruit } \\
\hline Oranges & 62 & 18.8 \\
\hline Apple & 62 & 18.8 \\
\hline Pineapple & 47 & 14.2 \\
\hline Watermelon & 46 & 13.9 \\
\hline Pawpaw & 37 & 11.2 \\
\hline Banana & 35 & 10.6 \\
\hline Others & 41 & 12.4 \\
\hline \multicolumn{3}{|c|}{ Most frequently consumed fruit } \\
\hline Orange & 94 & 24.5 \\
\hline Watermelon & 80 & 24.2 \\
\hline Pineapple & 43 & 13.0 \\
\hline Pawpaw & 30 & 9.1 \\
\hline Others & 83 & 25.2 \\
\hline \multicolumn{3}{|c|}{ Reason for the choice of fruit } \\
\hline Availability & 45 & 13.7 \\
\hline Convenience & 8 & 2.1 \\
\hline Attractiveness & 8 & 2.4 \\
\hline Cost & 21 & 6.4 \\
\hline Taste & 90 & 27.4 \\
\hline Health reasons & 23 & 7.0 \\
\hline No specific reason & 135 & 41.0 \\
\hline
\end{tabular}


Table 3: Vegetable consumption pattern among adults in Lagos, Nigeria

\begin{tabular}{|c|c|c|}
\hline Vegetable consumption & Frequency $(n=330)$ & Percentage (\%) \\
\hline \multicolumn{3}{|l|}{ Pattern of consumption } \\
\hline As part of main meal & 249 & 75.3 \\
\hline In between meals alone as snacks & 22 & 6.7 \\
\hline As main meal alone & 4 & 1.2 \\
\hline Not planned, anytime & 46 & 14 \\
\hline As dessert & 9 & 2.7 \\
\hline \multicolumn{3}{|l|}{ Form of consumption } \\
\hline Fresh raw vegetables/salad & 22 & 6.7 \\
\hline Cooked vegetables & 304 & 92.1 \\
\hline Juice & 4 & 1.2 \\
\hline \multicolumn{3}{|l|}{ Most preferred vegetable } \\
\hline Pumpkin (Ugu) & 112 & 33.9 \\
\hline Water leaf & 46 & 13.9 \\
\hline Celosia (efo soko) & 41 & 12.4 \\
\hline Cucumber & 23 & 7 \\
\hline Green leaf & 21 & 6.4 \\
\hline Okra & 15 & 4.6 \\
\hline Jute mallow & 12 & 3.6 \\
\hline Others & 60 & 18.2 \\
\hline \multicolumn{3}{|c|}{ Most frequently consumed vegetable } \\
\hline Pumpkin (Ugu) & 111 & 33.6 \\
\hline Celosia (efo soko) & 29 & 8.8 \\
\hline Okra & 27 & 8.2 \\
\hline Water leaf & 22 & 6.7 \\
\hline Green leaf & 17 & 5.2 \\
\hline Jute mallow & 15 & 4.6 \\
\hline Cucumber & 12 & 3.6 \\
\hline Others & 97 & 29.4 \\
\hline
\end{tabular}

Table 4: Average number of servings of fruits and vegetables consumed per day

\begin{tabular}{lcl}
\hline Average no of servings consumed daily & Frequency & Percentage \\
$1-2$ & 105 & 31.8 \\
$3-4$ & 136 & 41.2 \\
$>5$ & 89 & 26.9 \\
\hline
\end{tabular}


Table 5: Factors associated with adequate daily intake of fruits and vegetables among adults in Lagos, Nigeria.

\begin{tabular}{lrrrrr}
\hline $\begin{array}{l}\text { Socio-demographic } \\
\text { characteristics }\end{array}$ & $\begin{array}{l}\text { Adequate } \\
\text { intake } \\
\text { Freq (\%) }\end{array}$ & $\begin{array}{l}\text { Inadequate } \\
\text { intake } \\
\text { Freq (\%) }\end{array}$ & Total & $\mathbf{X}^{\mathbf{2}}$ & P-value \\
\hline Age (years) & $35(24.0)$ & $111(76.0)$ & 146 & 7.30 & 0.06 \\
$18-28$ & $25(23.2)$ & $83(76.9)$ & 108 & & \\
$29-38$ & $22(41.5)$ & $31(58.5)$ & 53 & & \\
$39-48$ & $7(30.4)$ & $16(69.6)$ & 23 & & \\
$=49$ & & & & & \\
Sex & $44(22.0)$ & $156(78.0)$ & 200 & 5.74 & 0.02 \\
Male & $45(34.6)$ & $85(65.4)$ & 130 & & \\
Female & & & & & \\
Marital status & $31(18.1)$ & $140(81.9)$ & 171 & 14.11 & 0.01 \\
Single & $56(36.6)$ & $97(63.4)$ & 153 & & \\
Married & $2(33.3)$ & $4(66.7)$ & 6 & & \\
Separated/divorced & & & & & \\
Level of education & $3(100.0)$ & $0(0.0)$ & 3 & 12.38 & 0.02 \\
No education & $2(10.0)$ & $18(20.0)$ & 20 & & \\
Primary & $48(25.3)$ & $142(74.7)$ & 190 & & \\
Secondary & $32(30.2)$ & $74(69.8)$ & 106 & & \\
Tertiary & $4(36.4)$ & $7(63.6)$ & 11 & & \\
Post- graduate & $23(18.3)$ & $103(81.8)$ & 126 & 8.73 & 0.03 \\
Estimated monthly income(naira) & $43(30.5)$ & $98(69.5)$ & 141 & & \\
$<20000$ & $16(35.6)$ & $29(64.4)$ & 45 & & \\
20000-50000 & $7(38.9)$ & $11(61.1)$ & 18 & & \\
$50001-100000$ & & & & & \\
$>100000$ & & & & \\
\hline
\end{tabular}




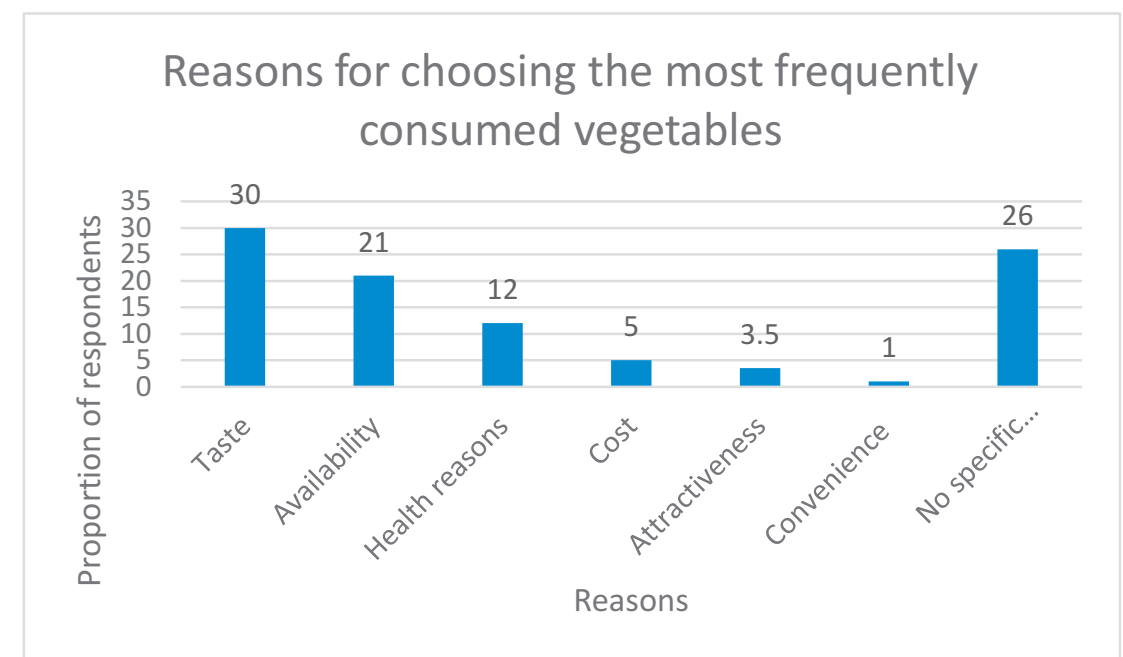

Figure 1: Reasons for choosing the most frequently consumed vegetable

Adequacy of daily intake of fruits and vegetables

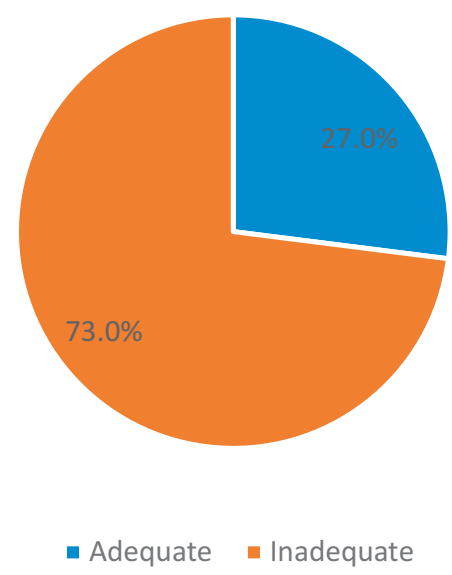

Figure 2: Prevalence of adequate intake of fruits and vegetables 